\title{
El control fiscal y su incorporación al sistema de pesos y contrapesos en Colombia
}

\author{
Paulo Bernardo Arboleda Ramírez* \\ Milton César Jiménez Ramírez** \\ Carolina del Pilar López Osorio***
}

\begin{abstract}
RESUMEN
En el presente artículo se estudia el control fiscal establecido en la Constitución Política de Colombia desde un enfoque hermenéutico jurídico, a partir del análisis de los principales fundamentos y modalidades de este mecanismo de control, tales como el control posterior y el concomitante frente a los actos y decisiones de la administración pública. Posteriormente se pasará a identificar algunos de los principios que guían la ejecución de esta actividad de control, para luego plantear la incorporación de la vigilancia fiscal dentro del sistema de pesos y contrapesos. Por último, se concluye que el control fiscal es un mecanismo constitucional para proteger el patrimonio público en el marco de un ejercicio activo del principio de pesos y contrapesos y la intervención ciudadana.
\end{abstract}

Control fiscal; Constitución; pesos y contrapesos

\section{Fiscal control and its incorporation to the system of checks and balances in Colombia}

\begin{abstract}
In this article, the fiscal oversight established in the Political Constitution of Colombia is studied from a legal hermeneutic approach, from the analysis of the main foundations and modalities of this control mechanism, such as subsequent and concomitant control against acts and decisions of
\end{abstract}

* Abogado y Magíster en Derecho, Universidad de Medellín, Colombia. Docente del Departamento de Jurídicas, Universidad de Caldas, Colombia. ORCID: 0000-0002-9217-7203. Correo electrónico: paulo. arboleda@ucaldas.edu.co

** Abogado de la Universidad de Caldas, Colombia. Doctor en Derecho, Universidad Carlos III de Madrid, España. Docente investigador del Departamento de Jurídicas, Universidad de Caldas, Colombia. ORCID: 0000-0003-1149-4723.Correo electrónico: milton.jimenez@ycaldas.edu.co

*** Abogada de la Universidad Libre, Colombia. ORCID: 0000-0001-9032-6503 . Correo electrónico: carolina.26417123535@ucaldas.edu.co

Este artículo de investigación es producto de una estrategia de cohesión investigativa en el marco del proyecto de investigación: "Políticas públicas y Democracia deliberativa" y de la política de producción investigativa del Centro de Investigaciones Sociojurídicas (CIS) de la Universidad de Caldas.

Artículo recibido el 4.5.20 y aceptado para su publicación el 8.1.21. 
the public administration. Subsequently, some of the principles that guide the execution of this control activity will be identified, and then the identification of fiscal surveillance within the system of checks and balances will be planted. Finally, it is concluded that fiscal control is a constitutional mechanism to protect public patrimony within the framework of an active exercise of the principle of checks and balances and citizen intervention.

Fiscal control; Constitution; check and balances

\section{INTRODUCCIÓN}

$\mathrm{E}$ ste trabajo sostiene que el control fiscal establecido en el artículo 267 de la Constitución Política de 1991, constituye un modelo de vigilancia frente a los actos y decisiones de la administración pública que puedan comprometer el patrimonio público, por lo que debe entenderse como una labor especializada que hace parte del sistema de pesos y contrapesos. El control fiscal se ejerce de forma posterior y paralela (concomitante) a los actos y decisiones de la administración. Su modalidad posterior fue diseñada por el constituyente originario, a su vez, el control concomitante fue implementado por el legislador como constituyente derivado ${ }^{1}$.

Este trabajo presenta el control fiscal como una especie del sistema de pesos y contrapesos, en donde la Contraloría General de la República se establece como un órgano especializado en la inspección, control y vigilancia del patrimonio público, asegurando su adecuada inversión, uso y optimización por parte de los agentes de la administración pública y de los particulares que ejercen funciones públicas. Antes de la Constitución Política de 1991, el control fiscal consistía en la revisión numérica legal de las cuentas que rendían los responsables del erario y de las erogaciones realizadas por la administración, confrontando que estos actos se ajustaran a las normas que le servían de sustento, para ello se ejercía un control previo a la toma de decisiones por parte del ente vigilado ${ }^{2}$. Esta modalidad fue sustituida por el control posterior, ya que la creciente actividad económica del Estado exigía un control integral (legal, financiero, disciplinario, administrativo, etc.) y no simplemente un control numérico legal que reducía a las Contralorías en entes de revisión técnica y en coadministradores ${ }^{3}$.

Bajo el Estado Social de Derecho el control fiscal debe centrarse en la vigilancia estricta de la protección, optimización y mantenimiento del patrimonio público, entendiendo por este todos los recursos del Estado destinados a la satisfacción de los derechos de los ciudadanos. El control fiscal se debe enmarcar en la vigilancia del Estado, en que sus acciones, decisiones y operaciones respondan a los principios de eficiencia, economía, equidad y valoración de los costos ambientales ${ }^{4}$.

\footnotetext{
${ }^{1}$ Acto Legislativo 04, 2019.

${ }^{2}$ Algunas normas que reglamentaron el control fiscal fueron: Ley 23, 1923; Ley 58, 1946; Ley 20, 1975.

3 Amaya, 2000.

${ }^{4}$ Ley 42, 1993, artículo 8. Consejo de Estado, 10/05/2007, Sentencia 2003-00182-01.
} 
A partir de la aplicación del método bibliográfico con un enfoque analítico y hermenéutico jurídico, se abordarán los siguientes tópicos: primero, se explicará el concepto y alcance del control fiscal posterior y selectivo, al igual que el control concomitante, como parte del sistema integral de control fiscal diseñado por el constituyente originario y por el constituyente derivado. Para ilustrar la aplicación del control fiscal se expondrán brevemente un par de casos; segundo, se expondrán los principios constitucionales fundantes del control fiscal en Colombia, con el propósito de evidenciar el carácter sistémico de esta función; tercero, se mostrará el control fiscal como una actividad que materializa el sistema constitucional de pesos y contrapesos, y que puede optimizarse bajo una práctica democrática centrada en el diálogo ciudadano y legislativo. Se concluirá que el control fiscal es un mecanismo constitucional para proteger el patrimonio público en el marco de un ejercicio activo del principio de pesos y contrapesos y la intervención ciudadana.

\section{El CONTROL FISCAL COMO GARANTÍA DEL PATRIMONIO PÚBLICO}

El control fiscal es una función pública que pretende salvaguardar el patrimonio estatal y representa una materialización del sistema de pesos y contrapesos; una tarea especializada en revisar la gestión de los recursos por parte de los órganos que componen el poder público, o de personas o entidades de derecho privado que participan de tal gestión. El control fiscal es un medio constitucional para asegurar la probidad de la función pública, del Estado y fomentar una ejecución de lo público para lo público, una que concrete el bien común y salvaguarde los bienes básicos que prioriza una sociedad: la salud, la educación, la infraestructura, la seguridad, entre otros propios de cada Estado.

Esta labor es ejecutada por disposición constitucional y, por lo general, se representa en una vigilancia posterior y selectiva de las actividades, procesos y decisiones que adoptan las entidades sometidas al control, así como de los resultados que producen. Este control es también selectivo porque el titular de la función de control fiscal elige técnicamente una muestra representativa de los procesos misionales encomendados a cada entidad o persona sujetas a control y, a partir de ellas, funda sus conclusiones y decisiones respecto del cumplimiento de la Constitución y la ley ${ }^{5}$. El control posterior y selectivo implica aceptar la incapacidad institucional para revisar todos los procesos de las entidades objeto de control, además se trata de un control que opera sobre hechos consumados o en ejecución, esto con el fin de evitar que el control fiscal afecte en el proceso de decisión autónoma del sujeto controlado.

Pese a la orden constitucional de que el control fiscal será posterior, han surgido otras modalidades que pretenden controlar de forma más estricta y real las decisiones de las entidades públicas, es el caso del control concomitante, que fomenta una vigilancia paralela al proceso decisional de la entidad, e incluso de los resultados que pretende obtener. Esto supone que la entidad objeto de control mantiene su autonomía para

\footnotetext{
${ }^{5}$ Ley 42, 1993, artículos 5-6.
} 
identificar necesidades o problemas a resolver, por lo que no puede ser cuestionada, e incluso por los medios que adopta, dándose que la vigilancia se aplicará sobre la proporcionalidad de los medios elegidos, los resultados alcanzados y la afectación objetiva del patrimonio público.

El control posterior y selectivo no tiene la connotación de principio, pues la vigilancia de la gestión fiscal del Estado se fundamenta en los principios de la función pública $^{6}$, como la eficiencia, la economía, la eficacia, la equidad y la valoración de los costos ambientales, de tal manera que permita establecer, en un período determinado, que la asignación de recursos sea la más conveniente para maximizar los resultados buscados por la administración pública; la que tendrá que buscar siempre los menores costos para los bienes conseguidos en igualdad de condiciones y bajo la calidad más adecuada para desarrollar sus objetivos y metas ${ }^{7}$. Así, el control posterior es una metodología o un instrumento para lograr la realización de los mandatos estipulados en los principios constitucionales.

\section{El control fiscal posterior y selectivo}

El control posterior, e incluso el concomitante, deben centrarse en identificar las relaciones económicas dadas entre el Estado y los ciudadanos, entre las entidades territoriales y demás sectores económicos, así como en la vigilancia de la gestión fiscal encomendada legalmente a los particulares; debe enfocarse en la justificación de la necesidad que desea cubrirse con la utilización de recursos públicos; en el balance entre costos y beneficios para estimar el impacto en las finanzas públicas, lo que supone valorar la afectación del patrimonio ambiental y cultural; en consecuencia, evaluar la gestión de la protección, conservación, uso y explotación de todo el patrimonio estatal.

El ejercicio del control fiscal posterior y selectivo implica que la Contraloría General de la República y los órganos que complementan el sistema de control fiscal, como las Contralorías departamentales y municipales ${ }^{8}$, deben organizar sus actividades administrativas con apego al principio de legalidad, esto es, organizar las funciones necesarias para ejercer la vigilancia del patrimonio público siguiendo estrictamente sus competencias, evitando caer en la prohibición de coadministración. La Constitución dispuso la autonomía administrativa y presupuestal de las entidades que ejercen el control fiscal con el fin de mantener su probidad, independencia e imparcialidad, dotándolas de la capacidad necesaria para cuestionar objetivamente las actuaciones de las entidades públicas y particulares encargadas del uso y preservación del patrimonio público; es decir,

${ }^{6}$ Constitución Política de Colombia, 1991, artículo. 209.

${ }^{7}$ Ley 42, 1993, artículo 8.

${ }^{8}$ Ley 136, 1994, artículo156, modificado por la Ley 617, 2000, artículo 21. Esta norma establece que los municipios y distritos clasificados en categoría especial y primera, y aquellos de segunda categoría que tengan más de cien mil habitantes, podrán crear y organizar sus propias Contralorías. También dispone que en los municipios en los que no haya Contraloría la vigilancia le corresponderá a la Contraloría departamental. 
el sistema fiscal se centra en el mantenimiento de la transparencia y en la persecución de la corrupción o de la extralimitación de la administración pública.

Esa autonomía se confronta frente a la autonomía de la administración pública y de las entidades territoriales, dándose que los hallazgos acerca de actuaciones e irregularidades en el cumplimiento de la legalidad, de la planeación, del mantenimiento y la optimización del patrimonio estatal deben fundarse en hechos específicos y probados; al igual que valorados con claridad y suficiencia, por su apego al sistema jurídico y su contundencia interpretativa y argumentativa, ya que los señalamientos fiscales no solo fundamentan la responsabilidad fiscal, sino también posibles responsabilidades administrativa, disciplinaria y penal. En ningún caso los señalamientos fiscales pueden pretender la adopción de ciertas opciones administrativas, ya que la identificación de necesidades, su justificación técnica, jurídica y financiera, su planeación y la manera de solucionarlas son una potestad exclusiva del administrador público.

Cuando se formula un hallazgo fiscal debe garantizarse el debido proceso administrativo y valorar objetivamente las razones alegadas por la entidad cuestionada, solo así será posible fundar las motivaciones que requiere el fallo administrativo fiscal, esto es, que la responsabilidad fiscal debe establecerse bajo el estricto seguimiento del debido proceso e ir más allá del restablecimiento del patrimonio, al optar por la promoción de las medidas orientadas al mejoramiento institucional. La falta de evaluación objetiva, probatoria y de motivación suficiente ponen en vilo el fallo fiscal, y constituye una vía de hecho, que debe ser controlada con los medios de impugnación administrativos y judiciales.

\section{El control concomitante como un complemento constitucional}

El control concomitante y preventivo es un complemento del control fiscal posterior y selectivo, consagrado como el medio originario de vigilancia en la Constitución. Este mecanismo implica que se excluyen opciones para el legislador o el constituyente derivado, destinadas a la creación del control previo, ya que un control de esta naturaleza supondría la potestad del ente fiscalizador de participar o censurar el proceso decisional del ente controlado9 . Empero, la orden constitucional no excluye mecanismos de control coherentes o coexistentes con el control posterior, controles preventivos o paralelos que permitan optimizar o complementar la probidad institucional, y más si se conciben

${ }^{9}$ Corte Constitucional, 11, 04, 2015, Sentencia C-103. Esta declaró inexequible el numeral $7^{\circ}$ del artículo $5^{\circ}$ del Decreto 267 de 2000, "Por el cual se dictan normas sobre organización y funcionamiento de la Contraloría General de la República”. La Corte encontró que los controles preventivos y la formulación de advertencias que la propia Administración, mediante las facultades atribuidas a las Superintendencias, son complementos al control fiscal. Esta Corporación explicó "que la función de advertencia que dicha norma atribuye a la Contraloría General de la República, si bien apunta al logro de objetivos constitucionalmente legítimos, relacionados con la eficacia y eficiencia de la vigilancia fiscal, desconoce el marco de actuación trazado en el artículo 267 de la Constitución, el cual encuentra dos límites claros, el carácter posterior y no previo, y la prohibición de coadministración de las funciones de las entidades controladas”. 
como resultado de momentos de madurez constitucional o como una respuesta a la creciente corrupción ${ }^{10}$.

El control concomitante puede complementar y optimizar el diseño constitucional del control fiscal, especialmente porque es un mecanismo que no suplanta ni presiona el proceso decisional de la administración pública, o de la persona que administra recursos públicos; su discrecionalidad y la necesidad de justificar sus decisiones se mantienen incólumes. La vigilancia se activa de forma selectiva y preventiva para cooperar con el cumplimiento de los fines constitucionales y legales, y asegurar resultados transparentes y oportunos para las demandas sociales ${ }^{11}$.

El principio de colaboración armónica fomenta relaciones de cooperación y control entre las ramas del poder público, como expresión de los principios de separación de poderes y del sistema de pesos y contrapesos; se trata de un diseño constitucional en pro de la garantía de los derechos pero también de consolidación de lo público como un fin común; la misma premisa se predica frente a los órganos especializados de control fiscal, quienes asumen una responsabilidad directa por la integridad patrimonial del Estado, e incluso por los resultados de su política. No se puede entender el control fiscal como un mero espectador, sino como un vigilante activo en el marco de sus competencias, como un órgano que advierte y revisa el apego a la legalidad y a la planificación para definir la corrección de los resultados de la gestión pública.

Existen razones constitucionales para admitir un control complementario del diseño original de la Constitución, al igual que razones prácticas vinculadas con la idea de que la constitución es un proceso viviente ${ }^{12}$. Un proceso que se adecua al paso del tiempo, que leen actores como el legislador y el poder constituyente, y que debe ser interpretado

${ }^{10}$ Conforme a los informes realizados por Corporación Transparencia por Colombia, 2019. Conforme a los informes de esta Corporación, entre enero del 2016 y julio del 2018, "el 6\% de los hechos de corrupción reportados corresponden a corrupción política y están asociados principalmente a irregularidades como compra y venta de votos durante la jornada electoral, violación a las leyes de financiamiento de campañas y presiones a funcionarios públicos y/o contratistas para votar a favor de candidatos. El $7 \%$ de los hechos de corrupción registrados afectaron el ámbito electoral, con casos como participación de grupos armados ilegales en jornadas electorales, sanción a partidos por otorgar avales a candidatos inhabilitados u obstrucción de procesos de revocatoria del mandato. El 30\% de actores involucrados en hechos de corrupción fueron autoridades electas por voto popular". Estas cifras evidencian altos índices de corrupción y crisis institucional en la aplicación de los controles especializados.

${ }^{11}$ Constitución Política, 1991, artículo 119.

12 Ackerman, 2011, pp. 89-114. Corte Constitucional, 02.07.2014, Sentencia C-418. El derecho viviente es una metáfora en la que el derecho de los libros y de las normas jurídicas no existe solo, sino que hay otro derecho que surge de las dinámicas sociales y que es el que se aplica a partir de la interpretación que realizan los órganos competentes. La Corte, ha manifestado que esta doctrina le permite "no basar los análisis de constitucionalidad en interpretaciones hipotéticas o descontextualizadas de las leyes, sino tomar como referencia las que han sido depuradas por los órganos de cierre de cada jurisdicción. Corte Constitucional, 30.09.2003, Sentencia C-875: La Corte establece unos requisitos para que se configure el derecho viviente; “(1.) la interpretación judicial debe ser consistente, así no sea idéntica y uniforme; (2) la interpretación judicial debe estar consolidada: Un solo fallo resultaría insuficiente para apreciar si una interpretación se ha extendido dentro de la jurisdicción; y, (3.) la interpretación judicial debe ser relevante para fijar el significado de la norma objeto de control". 
conforme con los hechos que limitan la Constitución, pretendiendo menguar su primacía y generar un estado oculto carente de control, donde prima la democracia transaccional o de intereses, lo que reduce el Estado de derecho.

El control fiscal y los demás instrumentos del sistema de pesos y contrapesos son determinantes para la democracia y el Estado de derecho. Valga decir, para que el servicio público llegue a todos los ciudadanos de forma igualitaria y sin privilegios ${ }^{13}$, para que los recursos disponibles se optimicen y se distribuyan respondiendo a necesidades reales; para que los privados u otros entes del Estado interesados en suplir necesidades mediante la contratación pública concurran de forma libre, igualitaria y transparente. Esto implica la necesidad para una democracia de instituciones públicas fuertes, sostenibles y que rindan cuentas y asuman la responsabilidad jurídica y política por ello ${ }^{14}$. Solo instituciones fuertes son capaces de brindar un trato igualitario a los ciudadanos y ayudar a extender la satisfacción de los deberes del Estado, pero alternadamente para ayudar a consolidar la idea de que la legalidad es seria, contundente e indistinta de las condiciones personales y económicas de los ciudadanos, de un Estado de derecho y no de un Estado sumido a intereses personales e infractor de la Constitución ${ }^{15}$.

En caso contrario, se fomentan bajos niveles de igualdad, de carácter republicano o del gobierno de los ciudadanos, de un gobierno virtuoso y que se toma los principios en serio ${ }^{16}$; se reduce la democracia pues existen menos oportunidades para que los ciudadanos participen en las decisiones que les interesan y en la vigilancia del patrimonio público $^{17}$. Una administración con un control reducido o que llega tarde, inoportuno, hace una democracia irreal y delegativa ${ }^{18}$, sustituida solo por las prácticas que distancian al ciudadano del ejercicio del poder.

Esto hace que el Estado se fraccione, que haya lugares con mayor o menor presencia del Estado, que se vea un Estado en lo central y otro en la periferia, unos donde aplica

13 Montaña, 2005, p. 29-45.

${ }^{14}$ Robinson y Acemoglu, 2012, pp. 95-101.

${ }^{15}$ Corte Constitucional, 02.12.1998, Sentencia SU-747. .La acepción de Estado de derecho contiene de manera implícita el respeto del ordenamiento jurídico por parte del Estado en sus actuaciones, las cuales están regidas por normas jurídicas en coherencia jerárquica con la Constitución. La acepción Estado de derecho implica que el Estado está limitado por la legalidad, sin que pueda hacer más de lo que expresamente puede.

16 Arango, 2014, pp. 179-196; Corte Constitucional, 27.04.2017, Sentencia C-253; 01.06.2016, sentencia C-285. El principio republicano junto a la separación de poderes se constituyen en los ejes articuladores que definen el régimen constitucional propio de la democracia liberal. Convirtiéndose estos principios en límites del poder político para evitar la arbitrariedad y el desconocimiento de los derechos del individuo. La Corte Constitucional ha sostenido que "la existencia de un poder limitado opera como garantía para el funcionamiento de la democracia y el sistema republicano de Gobierno, el cual parte de la base del equilibrio entre los poderes del Estado, el reconocimiento de ámbitos de ejercicio independiente y autónomo de las funciones otorgadas por el orden jurídico, y la subordinación de la actuación de los servidores públicos y los particulares a las reglas jurídicas”.

17 Jiménez y Arboleda, 2015, pp. 76-79.

${ }^{18}$ Este concepto alude a regímenes donde la democracia queda reducida al sistema electoral, al voto de las mayorías, en el cual se le entrega el poder público al líder carismático de turno. Ver: O’Donnell, 1994; 1998; Durkheim, 1959; Ferrajoli, 2009. 
la ley y otros donde se imponen criterios caprichosos, o de transacciones políticas que doblegan la ley. Esto lleva al denominado apartheid institucional ${ }^{19}$, un fenómeno en que el Estado es incapaz de llegar a todos los sectores sociales, donde las minorías se sumen en la ausencia de servicios públicos, en sus necesidades insatisfechas, creando un estado de cosas donde prima la desigualdad y se suplanta la Constitución. Por esto, el control fiscal concomitante puede ser un medio efectivo y proporcional para optimizar la supremacía constitucional.

Ahora bien, el control fiscal en la historia de Colombia se identificó directamente con el examen de las actuaciones de los responsables del manejo del erario con la finalidad de establecer, con una pretensión de absoluta exactitud de la información de la hacienda pública en todos los sectores, la coherencia y transparencia en los sistemas contables y presupuestales ${ }^{20}$. Bajo esta óptica, el control concomitante y preventivo se establece bajo el sistema de auditoría a la gestión y resultados de la administración ${ }^{21}$ y como complemento del control posterior y selectivo implementado en la Constitución, el que se orienta preponderantemente a la vigilancia integral, no solo numérica, de la adecuada inversión de los recursos del Estado y del aseguramiento del cumplimiento de los fines esenciales del Estado social de derecho y de los objetivos misionales de los organismos controlados ${ }^{22}$.

De acuerdo con la exposición de motivos del Acto Legislativo 04 de $2019^{23}$, los nuevos sistemas de control que se establecen, buscan solucionar la inoportunidad que ha aquejado el control posterior y selectivo, haciendo que la vigilancia de la gestión fiscal en tiempo real sea efectiva, ${ }^{24}$ con el apoyo de herramientas tecnológicas que se acompasan con los nuevos conceptos de gerencia pública. El control concomitante y

${ }^{19}$ GARCía y EsPinOSA, 2013, pp. 108-110 y 119-121.

${ }^{20}$ González, 1979; Jaramillo y Colmenares, 1978; Tirado, 1983; López, 2015. Durante la formación de la República, Colombia atravesó grandes dificultades en la organización de la hacienda pública debido a la crisis económica generada por los gastos dirigidos al sostenimiento de la independencia y su deseo improvisado de conformarse como república; deseo constantemente truncado por las diferentes ideologías políticas federalistas y centralistas e intereses económicos de diferentes sectores. La preocupación de los gobiernos de turno era conocer con absoluta certeza las finanzas del Estado y contar con una información confiable para establecer sus ingresos y gastos y, poder cumplir con las onerosas obligaciones a acreedores tanto externos como internos; en consecuencia, se estableció la obligación a todas las oficinas y administraciones de la Hacienda Pública del Estado la revisión y fenecimiento de las cuentas que debían rendir los responsables del erario.

${ }^{21}$ El control numérico legal continúa vigente y acompaña otros procedimientos técnicos de auditoría que adelantan los órganos de control.

22 Naranjo, 2007, p. 33. Las falencias del control previo no fueron la única razón para que el Constituyente Primario decidiera mantener como única forma de control el posterior y selectivo. Al respecto, Naranjo ha estimado que "el paso a la auditoría de control de gestión y resultados implicó para las contralorías que llevaban un clásico control de cumplimiento normativo, la exigencia de ejercer un control vinculado a requerimientos más modernos que difieren cualitativamente de las formas anteriores. La diferencia de enfoque entre un sistema de auditoría tradicional y uno centrado en el control y resultados es fundamental, por cuanto el primero hace énfasis en las normas y procedimientos per se, y el segundo en pautas de rendimientos objetivas y medibles".

${ }^{23}$ Corte Constitucional, 06.05.2020, Sentencia C-140.

${ }^{24}$ Gaceta del Congreso, 2019, n 153. 
preventivo, promueve una vigilancia más contundente de la gestión fiscal, garantiza en tiempo real poder hacer seguimiento a las fuentes y usos del recurso público; igualmente, incorpora la función de advertencia, y la función de intervención para el mejoramiento del control fiscal nacional y territorial.

La función de advertencia se estableció en el Decreto Ley 267 de 2000, como una herramienta que facultó a la Contraloría para advertir acerca de operaciones o procesos en ejecución y evitar graves riesgos en el patrimonio público y, en consecuencia, ejercer el control posterior respecto de los hechos identificados. La Contraloría se encargó de regular su aplicación y procedencia en la Circular 005 del 21 de junio de 2007, delimitando su ejercicio a situaciones excepcionales o de grave riesgo de menoscabo de los bienes públicos.

La Contraloría en la Circular 005 especificó que no se trataba de control previo, pues se pretendía indicar, a la entidad vigilada, los posibles graves perjuicios a los intereses patrimoniales del Estado a causa de sus decisiones. Así, fruto del ejercicio de los sistemas técnicos de control fiscal la Contraloría emitía una formulación de adverten$\operatorname{cia}^{25}$. En la Exposición de Motivos del Proyecto de Acto Legislativo 355 de 2019, que reforma el régimen de control fiscal, la Contraloría General de la República documenta la importancia del control preventivo con las funciones de advertencia que dirigió a las entidades fiscalizadas entre el 2006 y 2015, por un valor de $\$ 25.671 .667 .051 .643$ (USD 6.477.757.418). Algunos ejemplos de la función de advertencia pueden ser:

a) La negociación de la empresa de Telecomunicaciones de Colombia-Telecom- en el 2006, en la que se logró un beneficio de USD 622 millones frente a negociaciones anteriores en las que se planteó una estimación inferior del patrimonio público. Al término de la subasta, el Contralor General de la República indicó que "la Nación logró tal beneficio adicional frente a lo previsto en el memorando de entendimiento convenido con Telmex en el año 2005"26.

b) La recuperación de dineros por concepto de IVA por parte de la Dirección de Impuestos Nacionales -DIAN- en el 2014. La DIAN recuperó \$222 mil millones por concepto de impuesto al valor agregado, al lograr transar con las aseguradoras este pago; la entidad atendió una función de advertencia de la Contraloría al Director de esta entidad acerca de los riesgos que podría generar la inoportuna gestión frente a este tema en la negociación. La Contraloría Delegada de Gestión Pública e Instituciones Financieras venía emitiendo recomendaciones desde el $2012^{27}$.

${ }^{25}$ Este instrumento de control fue objeto de dos pronunciamientos por parte de la Corte Constitucional. El primero fue la Sentencia C-967 de 2012 donde se expresa que la función de advertencia es un instrumento de colaboración armónica entre las entidades del Estado y, el segundo, la Sentencia C-103 de 2015 que declara su inexequibilidad al asimilarse al control previo.

\footnotetext{
${ }^{26}$ HERNÁNDEZ, 2006.

${ }^{27}$ Diario El Nuevo Siglo, 20 de mayo de 2014.
} 
La función de advertencia constituye un instrumento valioso en términos de oportunidad en la recuperación de los recursos públicos. Permite alertar acerca de la toma de decisiones futuras, estimar riesgos ciertos y notorios ${ }^{28}$, generar rendición de cuentas y deliberación pública acerca de la valoración económica, cultural, ambiental y social del patrimonio estatal. Reside en la práctica del control fiscal y en la cooperación administrativa el ejercicio prudente de esta función de advertencia -en cabeza del Contralor General-, pues debe darse con objetividad para evitar cuestionamientos infundados en contra de los entes controlados, lo que puede minar la confianza institucional y social ${ }^{29}$. La seriedad del instrumento deberá soportarse en fundamentos fácticos y probatorios contundentes y capaces de estimar adecuadamente, proteger y ayudar a recuperar los recursos públicos ${ }^{30}$, y no en sospechas, persecución política o en pugnas institucionales ${ }^{31}$.

\section{Dos casos de control fiscal}

Para ilustrar la aplicación y pertinencia del control fiscal se exponen brevemente dos casos en los que se evidencia la necesaria protección del patrimonio público y la protección de los derechos de la población:

\section{a) Programa de Alimentación Escolar -PAE-}

En el primer semestre del 2017, mediante el control posterior y mediante la auditoría de desempeño, la Contraloría General de la República evaluó el Programa de Alimentación Escolar ejecutado durante la vigencia 2016 para revisar aspectos financieros, contratación y condiciones del servicio, seleccionando para su estudio diversos departamentos y municipios.

Los resultados de la evaluación evidenciaron falencias relacionadas con aspectos financieros y presupuestales del programa, en cuanto a la asignación y trámite de los recursos, la falta de articulación entre los responsables, debilidades en su cobertura; cuestiones que afectaron la oportunidad y continuidad del servicio de alimentación escolar.

Empero, para evaluar las condiciones en la prestación del servicio y el mejoramiento de la situación alimentaria de los beneficiarios, el control posterior se queda corto, porque la evaluación de la Contraloría bajo esta modalidad se hace sobre procesos ejecutados y consolidados durante la vigencia que fue auditada. Entre tanto, el control preventivo y concomitante ha facilitado la revisión en tiempo real de la falta de inversión de recursos públicos para la garantía de los derechos de los niños, es así como durante el inicio de

${ }^{28}$ El riesgo inminente supera al riesgo inherente que se define como aquel al que se enfrenta una entidad en ausencia de acciones de la dirección para modificar su probabilidad de impacto. Departamento Administrativo de la Función Pública, 2018, pp. 36-87.

29 Gómez LeE, 2016, pp. 196-197.

${ }^{30}$ Contraloría General de la República, 24.03.2017, Resolución 012.

${ }^{31}$ Revista Dinero, 16 de abril de 2015. 
este año escolar y posteriormente con la crisis sanitaria se determinó que el $32 \%$ de las entidades territoriales no han contratado el PAE.

b) Medidas en Estado de Emergencia Económica y Social relacionado con el Covid-19.

Con ocasión de la pandemia la Contraloría expidió la Resolución Orgánica 0753 de 2020, para la aplicación del control concomitante y preventivo en la vigilancia de las medidas de emergencia económica y social adoptadas por el gobierno y demás entidades públicas. Con ello, el órgano fiscalizador pretende observar a los sujetos de control mientras adopta decisiones, sin intervenir en ellas. La Contraloría viene monitoreando en tiempo real la ejecución de los recursos cuya finalidad sea la atención de la emergencia económica y social que se atraviesa en la actualidad ${ }^{32}$.

En el caso preciso de la entrega de ayudas alimentarias por parte de municipios y departamentos a la población pobre y vulnerable, el ente fiscalizador viene efectuando un seguimiento continuo y permanente con el fin de corregir irregularidades relacionadas con sobrecostos en el valor convencional de los alimentos. Es así como en el Departamento de Arauca se encontraron sobrecostos en un contrato de suministro logístico y entrega de 33.437 kits de ayuda alimentaria a la población afectada por la emergencia sanitaria, lo que motivó la apertura de un proceso de responsabilidad fiscal contra el gobernador de Arauca, José Facundo Castillo, en cuantía de \$1.050 millones. El organismo de control estableció un presunto sobrecosto del $31 \%$ en los kits adquiridos por este contrato y presobrecostos en productos como sal $(145 \%)$, panela $(206 \%)$ y pasta $(211 \%)$, entre otras irregularidades ${ }^{33}$.

Además, la Unidad de Investigaciones Especiales contra la Corrupción ha iniciado indagaciones preliminares contra varias entidades públicas por sobrecostos en la adquisición de elementos de protección personal, suministro de insumos y dispositivos médico-quirúrgicos, sobrecostos en los pagos de pautas a medios impresos, digitales, radiales y televisivos de estrategias de comunicación relacionadas con la Emergencia Covid $19^{34}$. Asimismo, se reportaron a la Contraloría contratos con sobrecostos en ocho municipios, los que ajustaron sus contratos en cuantía de $\$ 5.699$ millones $^{35}$.

También se ha generado alertas relevantes en cuanto a la dotación al personal de salud con el material de protección necesario frente al riesgo de contraer Covid-19; lo pertinente a la recogida, embalaje y envío de las pruebas diagnósticas y un informe

\footnotetext{
${ }^{32}$ Contraloría General de la República, 23.04.2020, Comunicado de prensa 061. Contraloría General de la República, 24.04.2020, Comunicado de prensa 062.

33 Contraloría General de la República, 24.04.2020, Comunicado de prensa 063.

${ }^{34}$ Contraloría General de la República, 24.04.2020, Comunicado de prensa 063.

${ }^{35}$ Contraloría General de la República, 21.04.2020, Comunicado de prensa 058.
} 
preliminar realizado en todos los aeropuertos y terminales de transporte del país en relación con las acciones de prevención ${ }^{36}$.

\section{PRincipios FUndantes Del CONTROL Fiscal}

El control fiscal es un instituto constitucional que refuerza el control propio de la separación de poderes, su ejercicio compete a un órgano autónomo e independiente dedicado a la vigilancia de la gestión fiscal por parte de la administración y de particulares en el manejo de los recursos públicos. El control fiscal fomenta la probidad administrativa y financiera, el apego a los fines del Estado y de las instituciones públicas, constituye una vista externa y especializada frente al poder público sin menoscabo de la colaboración armónica entre las entidades públicas y el deber de control recíproco. Sin embargo, la Corte Constitucional ha establecido que no es admisible que una entidad del Estado realice revisiones de cuentas, control financiero, control de legalidad, control de gestión y control de resultados sobre otra, la que ejerce control sobre esta; esto es, se acabaría con la independencia, objetividad e imparcialidad, propias de un control fiscal eficiente y efectivo. Esto refuerza el rol y autonomía de la Contraloría, y advierte la necesidad de diseñar las instituciones estatales no solo desde sus fines y medios, sino también manteniendo la probidad del control; pues lo contrario generaría entes omnímodos.

Acerca de este principio y la función de control fiscal, la Corte Constitucional ha señalado ${ }^{37}$, conforme con los artículos 267, 268 y 272 de la Constitución, que la función de control no solo obedece a un criterio de división y especialización de las tareas públicas, sino también a la necesidad política y jurídica de controlar, vigilar y asegurar que las actuaciones de las entidades estatales se realicen bajo estrictos parámetros de corrección en la utilización, inversión y disposición de los fondos y bienes por parte de la Nación, los departamentos, distritos y los municipios.

El control fiscal está ligado al principio de legalidad ${ }^{38}$, ya que el control del gasto público funda su legitimidad en el respeto a la soberanía popular, esto es, a las decisiones emanadas de los representantes del pueblo y a la garantía de que el Estado está actuando de forma eficiente, celera y transparente ${ }^{39}$. Esto implica que la legalidad y su defensa son una expresión del interés general ${ }^{40}$ y social, de la materialización del Estado social de derecho, del deber del Estado de generar condiciones de igualdad material por medio de su gestión. Por ello, la vigilancia fiscal es la garantía de la legalidad de las operaciones financieras, económicas, administrativas o de cualquiera otra índole, para establecer si estas se ejecutaron conforme con las normas que las rigen, como resguardo de la validez

${ }^{36}$ Contraloría General de la República, 17.03.2020, Comunicado de prensa 038; 19.03.2020, Comunicado de prensa 041; 20.03.2020, Comunicado de prensa 043; 23.04.2020, Comunicado de prensa 060.

37 Corte Constitucional, 24, 08, 1995, Sentencia C-374.

38 Corte Constitucional, 16, 04, 2008, Sentencia C-335.

${ }^{39}$ Ley 42, 1993, artículos 8-13.

${ }^{40}$ Corte Constitucional, 07.07.2006, Sentencia T-517. 
ética de las actuaciones del Estado y como realización de la promesa de asegurar las condiciones mínimas para la vida digna de los ciudadanos ${ }^{41}$.

Además está el principio democrático ${ }^{42}$ que faculta al pueblo y a las organizaciones a intervenir en el ejercicio y control del poder público por medio de sus representantes o directamente ${ }^{43}$. Esto se traduce en la democracia participativa a la que se ha referido la Corte Constitucional indicando que, sin la participación activa de los ciudadanos en el gobierno de los propios asuntos, el Estado se expone a una pérdida irrecuperable de legitimidad como consecuencia de su inactividad frente a las cambiantes y particulares necesidades de los diferentes sectores de la sociedad ${ }^{44}$. En consonancia con el principio democrático, la Contraloría General de la República ha implementado el control fiscal participativo, el que fomenta la participación mediante organizaciones ciudadanas, asambleas, juntas de acción comunal, y el apoyo a las veedurías ciudadanas ${ }^{45}$.

En cuanto a la moralidad administrativa ${ }^{46}$ se impone al ente fiscalizador un seguimiento detallado del cumplimiento de los deberes jurídicos de la administración pública, de velar por su sujeción a la ley, por no incurrir en omisiones o extralimitaciones en el ejercicio de sus funciones. La moralidad administrativa no solo consiste en predicar los principios de eficiencia, eficacia, economía, equidad, publicidad y transparencia, sino en promover y verificar la asunción por parte del servidor público de la moralidad política impresa en la Constitución, es decir, en constatar que el servidor público es un servidor de los derechos y de la Constitución ${ }^{47}$. Por ello, un Estado de derecho que ejerce un régimen de transparencia debe contar con instrumentos jurídicos que hagan efectivos este principio, como el régimen de inhabilidades, incompatibilidades y prohibiciones de los servidores públicos. El control disciplinario respecto del comportamiento del servidor y el control interno de gestión, esto es, la autorrestricción por parte del mismo Estado.

\section{EL CONTROL FISCAL Y EL PRINCIPIO DE PESOS Y CONTRAPESOS}

El principio de pesos y contrapesos constituye una garantía que optimiza el sistema de separación de poderes y especializa el control a las autoridades públicas, específicamente para la defensa de bienes centrales en la Constitución y en la vigencia del Estado de derecho, tales como la probidad de las autoridades en la defensa y uso del patrimonio

${ }^{41}$ Corte Constitucional, 12.07.2006, Sentencia C-529.

42 Arboleda y Jiménez, 2017.

${ }^{43}$ Corte Constitucional, 08.04.2015, Sentencia C-150.

${ }^{44}$ Corte Constitucional, 24.09.1992, Sentencia T-540.

${ }^{45}$ El control fiscal participativo está reglamentado en las leyes 489, 1998; 850, 2003.

${ }^{46}$ Corte Constitucional, 23.08.2012, Sentencia C-643. La moralidad administrativa no se circunscribe al fuero interno de los servidores públicos sino que abarca toda la gama del comportamiento que la sociedad espera de quienes manejan los recursos de la comunidad.

${ }^{47}$ Corte Constitucional, 13.11.2003, Sentencia C-826. 
público (Contraloría General) y la moralidad administrativa y la promoción de los derechos humanos (Procuraduría y Defensoría del Pueblo, o Ministerio Público).

En los papeles del Federalista, Madison defendió la idea de un sistema institucional que asegurara la defensa de lo público y evitara que las autoridades tomaran más poder del que se contemplaba para ellas en la Constitución. Su propuesta se focalizó en combatir toda concentración excesiva de poderes en una rama del poder público, o en otras entidades constitucionales; en evitar la tentación constante de acumular poder y avasallar los derechos de los ciudadanos y la distribución de poder definido constitucionalmente. Empero, el control de un posible abuso de poder debe ser moderado y proporcional, no puede ser que aquel que controla, genere una amenaza, que impida la acción esperada del poder público ${ }^{48}$.Este principio ha sido interpretado por la Corte Constitucional de Colombia como un modelo de optimización de la separación de poderes, exigiendo la colaboración armónica y el control recíproco entre las diferentes entidades. Bajo su jurisprudencia el constituyente de 1991 optó por un modelo en el que las funciones necesarias para cumplir los fines del Estado se desarrollan mediante órganos autónomos e independientes. El sistema de frenos y contrapesos tiene como finalidad lograr la armonización entre una mayor eficiencia del Estado y al mismo tiempo garantizar una esfera de libertad para sus asociados que se materializa por medio de la limitación del poder y la distribución y articulación de competencias ${ }^{49}$.

Un sistema de pesos y contrapesos debe equilibrar la relación entre los órganos del Estado y evitar poderes omnímodos o sin control. La Contraloría General de la República se presenta como un órgano especializado en la inspección, control y vigilancia del patrimonio público, en su adecuado uso, inversión, preservación y optimización, con la capacidad de limitar los actos irregulares de los mandatarios electos popularmente y de la administración pública en general, así como de los particulares que ejercen funciones públicas. Por eso ha sido dotada del poder de adelantar procesos administrativos sancionatorios, e incluso de inhabilitar a los funcionarios encontrados responsables fiscalmente. A su vez este acto sancionatorio puede ser controlado vía judicial mediante la acción de nulidad por vicios de ilegalidad o de inconstitucionalidad, empero, no se trata de un procedimiento judicial como lo requiere la convención interamericana de derechos humanos ${ }^{50}$, lo que implicaría un debate respecto de la convencionalidad de esta previsión de la Constitución.

Este control por principio constitucional se ejerce de forma posterior-decisión del constituyente originario- y de forma paralela o concomitante a los actos y decisiones de la administración - por decisión del legislador como constituyente derivado-. La función de control fiscal en el marco de un Estado Social de Derecho y de la teoría de pesos y contrapesos, se concibe como estructura esencial para el logro de los fines de transparencia

\footnotetext{
${ }^{48}$ Hamilton, et. al., 1982, numeral 51.

${ }^{49}$ Corte Constitucional de Colombia, 10.07.2019, sentencia C-306.

${ }^{50}$ Convención Interamericana de Derechos Humanos, 1978, artículo 23.
} 
y eficiencia en la actividad estatal ${ }^{51}$. Implica que la discrecionalidad gubernamental y administrativa está siendo observada para evitar la consolidación de las vías de hechos, o de cualquier actuación contraria al carácter público del Estado.

El control fiscal representa una confrontación necesaria para moderar los motivos del gobierno y la administración pública, para contener el egoísmo propio de cada administrador o de la porción de poder público distribuido en el acuerdo constitucional. Exige la necesaria justificación desde la Constitución, los derechos de los ciudadanos y los fines del Estado, así como desde la planeación para establecer qué se hará, cómo se hará, con qué recursos y qué impacto se espera obtener; bajo estos tópicos la evaluación fiscal determinará si se ha actuado con moderación y abrigo constitucional y legal. El desbordamiento del control, así como cuestionar indebidamente la administración, o presionar e inmovilizar la gestión pública, puede ser a su vez controlada administrativa y judicialmente. El controlador y el controlado se ven sometidos a un desacuerdo que hace parte de su misión y de las consagraciones propias de un sistema de pesos y contrapesos ${ }^{52}$.

\section{La democracia como complemento del diseño constitucional del control fiscal}

Pese a sus fundamentos filosóficos el sistema de pesos y contrapesos requiere de un diseño constitucional importante, no solo en cuanto a instituciones que frenen los posibles excesos del poder público, sino que también exige complementarse con elementos democráticos como:

a) La cultura institucional: una pertenencia por los valores y principios constitucionales y las exigencias de probidad, transparencia, publicidad y celeridad propias de la buena función pública y el Estado de derecho; esto implica entidades que trabajan bajo fundamentos de transparencia, no solo erradicando la corrupción, sino también evidenciando su planeación, su ejecución presupuestal y la eficacia de la misma en cuanto al servicio público y la satisfacción de los derechos de la población. Asimismo, la incorporación de procedimientos de seguimiento a la gestión pública por medios virtuales ${ }^{53}$ como instrumento de control social y participación ciudadana, sumado necesariamente a un sistema de rendición de cuentas.

b) La aceptación de que la gestión pública debe promover acciones coordinadas con las demás instituciones del Estado para garantizar un ejercicio efectivo, pero a la par, para incrementar el prestigio y la confianza social; la confianza institucional debe crecer por la capacidad de control y probidad probada. Los entes de control no pueden padecer una desconfianza absoluta con los entes controlados, promoviendo una paranoia institucional, lo que tampoco supone promover la creencia

${ }^{51}$ Corte Constitucional de Colombia, 17.08.2016, sentencia C-439.

52 Gargarella, 2013, pp. 6-7; Gargarella, 2014.

${ }^{53}$ Los medios virtuales utilizados por la Contraloría para evaluar en tiempo real los contratos en el marco de la crisis sanitaria por el Covid-19, han consistido en el cruce de informaciones contenidas en diferentes bases de datos acerca de contratos, servidores públicos, la plataforma Colombia compra eficiente, entre otras. 
de que las instituciones son movidas por seres virtuosos. Sin embargo, debe admitirse que justo el desacuerdo institucional potencia las posibilidades de control y contención frente a los excesos o la apropiación de lo público: la corrupción. La democracia deliberativa fomenta la comprensión y construcción progresiva del sistema de controles mediante la contradicción y la discusión colectiva y, en consecuencia, el mejor entendimiento del bien común ${ }^{54}$.

c) La necesidad de medidas internas de organización administrativa y de control interno de gestión y de la disciplina de los funcionarios, garantizando instancias operativas autónomas y, por tanto, no sujetas a presiones. Al efecto, el sistema de control fiscal en Colombia abarca la Contraloría General de la República, la que es vigilada por la Auditoría General de la Nación ${ }^{55}$; pese a las competencias de la Contraloría General ${ }^{56}$, los departamentos y algunos municipios pueden contar con Contraloría para su jurisdicción y como un mecanismo de autonomía territorial. Esto se suma a los sistemas de veedurías y a los canales abiertos para las peticiones y denuncias ciudadanas 57 .

d) El control fiscal como especie del sistema de pesos y contrapesos debe complementarse con un control social deliberativo. El diseño constitucional requiere en cualquiera de sus manifestaciones y objeto de control fomentar que la vigilancia y la crítica sean una constante mediante el principal método de materialización constitucional: la democracia ${ }^{58}$. La democracia asegura que con la participación igualitaria de los ciudadanos en los asuntos que les afectan ${ }^{59}$, puedan defender sus ideas y concepciones acerca de cualquier problema social, intercambiar ideas desde el respeto y el peso de los argumentos, y construir desde la moralidad política una respuesta colectiva y moralmente aceptable por todos ${ }^{60}$.

El ciudadano cuenta en la democracia constitucional con diversos mecanismos de participación que le permiten decidir, promover normas, decisiones y cuestionar las autoridades $^{61}$. Por tanto, el diseño constitucional no se cierra solo con la consagración de instituciones de control especializado, con la presunción de virtudes en los servidores públicos, en los principios de la función pública, o en la cultura institucional, sino que requiere necesariamente de un deber ético y propio de la vida del ciudadano en democracia: la cultura de diálogo y crítica al poder.

${ }^{54}$ WaLdRON, 2005.
${ }^{55}$ Corte Constitucional, 24.11.2004, sentencia C-1176.
${ }^{56}$ Corte Constitucional, 11.03.2015, Sentencia C-103.
${ }^{57}$ En Colombia el legislador entendió por veeduría ciudadana el mecanismo democrático de representación que le permite a los ciudadanos o a las diferentes organizaciones comunitarias, ejercer vigilancia de la gestión pública en todos los ámbitos del Estado.

58 DAHL, 1956.

59 Gargarella, 1996, p. 161-164.

${ }^{60}$ Nino, 1997, pp. 180, 192-194.

${ }^{61}$ Ley 1757, 2015. 
Desde luego, la apatía ciudadana está motivada en la crisis de representatividad y en la ausencia de legitimidad política de las instituciones ${ }^{62}$, la que no se agota con la fuente constitucional, sino que debe impulsarse constantemente por medio de un proceso de diálogo con el ciudadano ${ }^{63}$. Un diálogo en el que el ciudadano se incluya en la administración y la administración se sienta vinculada por el dictamen popular y deliberativo. En consecuencia, la administración debe implementar políticas y protocolos constantes para fomentar, mantener y sintetizar el diálogo social; en este contexto, las experiencias de foros y asambleas ciudadanas para establecer y vigilar la ejecución del presupuesto público ${ }^{64}$ resultan significativas y legitimantes.

\section{El foro legislativo y el control fiscal}

El legislador debe materializar las demandas ciudadanas y para ello debe participar en el trámite de los debates sociales, bien como un actor que interviene ante el gobierno y los juicios del control judicial de constitucionalidad, pero también como promotor del foro legislativo conforme con su poder de libre configuración ${ }^{65}$, esto es, su capacidad de crear normas bajo una alta discrecionalidad, siempre que respete los derechos humanos y la Constitución. Conforme con esto el legislador puede optimizar el principio de separación de poderes y el sistema de pesos y contrapesos en varios sentidos:

a) Como una garantía institucional que module el poder de las ramas del poder público y canalice la energía social proveniente de la política, la crítica y la protesta social, la que ha estado centrada en impugnar la falta de transparencia estatal ${ }^{66}$.

b) Para cooperar con las demás ramas del poder público y promover una legislación más legítima y deferente frente a los criterios técnicos y políticos de los demás actores institucionales ${ }^{67}$. Así, el control fiscal concomitante provino de un diálogo entre el órgano de control, el gobierno y el legislador, lo que generó una deferencia del control judicial de constitucionalidad y respondió a la creciente demanda de medios efectivos de vigilancia.

c) Como legislador ordinario para regular los niveles de control e intervención de los institutos que materializan el control fiscal y disponer sus potestades sancionatorias, u otros esquemas de control como el disciplinario, así como para disponer espacios de participación ciudadana ${ }^{68}$.

d) Como constituyente derivado el legislador puede modificar la Constitución para complementarla, interpretarla o enmendarla como una forma de diálogo

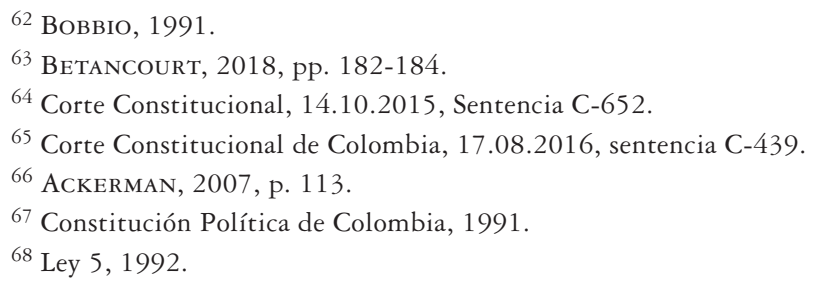


con el constituyente originario, quien estableció las leyes fundamentales de la Constitución que no podrán ser eliminados o limitados, pues tal posibilidad es solo competencia de su creador ${ }^{69}$. El legislador como constituyente derivado materializa y concretiza las leyes fundamentales del constituyente originario. Limitación que también impone no sustituir la Constitución ${ }^{70}$, esto es, no abolir sus leyes fundamentales o hacerlas impracticables, dándose que no podría tolerarse un control que elimine la capacidad de decidir o coaccionar la decisión del gobierno o la administración pública; pero a la par, no respetaría la Constitución una reforma que mengüe el control fiscal y lo convierta en algo simbólico o de mera recomendación.

Por ello, el constituyente derivado puede complementar la regla básica del sistema de pesos y contrapesos con disposiciones que incrementen el control a los gestores fiscales, como una medida dialógica de lo reclamado por los actores institucionales y sociales; el control fiscal y su reforzamiento mediante diversos mecanismos -como el control concomitante- para impulsar un mayor rigor en los principios de transparencia, moralidad y celeridad de la administración pública y controlar el mal de la corrupción. Incluso puede responder a criterios especializados como el que representa la experticia institucional de la Contraloría.

La reforma constitucional puede ser expresión de un diálogo abierto en el que los ciudadanos pueden expresar sus expectativas y pretender transformar, complementar e interpretar la Constitución, y de ello se debe encargar el foro legislativo, como escenario de la democracia deliberativa ${ }^{71}$. Una lectura democrática del sistema de pesos y contrapesos debe producir como resultado el incremento de mecanismos de mayor control y salvaguarda del patrimonio público como derecho colectivo, y por tanto, de la vigencia de la Constitución. Debe promover la deliberación como un mecanismo de balance entre mayorías y minorías, y en tal sentido, promover una nueva división y control del poder.

\section{Conclusión}

Se ha evidenciado que el control fiscal posee una estructura definida por medio del diseño constitucional dado por el constituyente originario y derivado, así como por los principios que impulsan una vigilancia activa del patrimonio público y una interacción entre las ramas del poder público capaz de optimizar el sistema de pesos y contrapesos. Es necesario comprender el control fiscal como un ejercicio necesario de este sistema, particularmente mediante la promoción del criterio objetivo del órgano de control fiscal, el legislador y especialmente del ciudadano, quien debe y puede intervenir en cualquier

\footnotetext{
69 SCHMiтT, 1983, p. 110.

70 Albert, 2019.

${ }^{71}$ Gargarella, 2014.
} 
asunto que afecte su Constitución y modo de vivir, específicamente cuando observa que aquello que les pertenece a todos es puesto en peligro por el mal de la corrupción.

\section{BiBLIOGRAFÍA}

Ackerman, Bruce, 2011: La Constitución viviente, Madrid: Marcial Pons.

Ackerman, Bruce, 2007: La nueva división de poderes, México: Fondo de Cultura Económica.

Albert, Richard, 2019: Constitutional Amendments: Making, Breaking, and Changing Constitutions, New york: Oxford

Amaya, Uriel, 2000: Fundamentos Constitucionales del Control Fiscal, Bogotá: Umbral Editores.

Arango, R, 2014: "La insuficiencia republicana de nuestras instituciones", Revista Temas SocioJurídicos, volumen XXXII, n 65.

Arboleda, Paulo y Jiménez, Milton, 2016: "Una aproximación a la filosofía política de la cláusula democrática en la Constitución de 1991”, Revista Filosofía UIS, volumen XV, n 1.

Betancourt, Guillermo, 2018: "Democracia participativa versus democracia territorial: participación, autonomía y desarrollo municipal”, Revista digital de Derecho Administrativo, 20.

Bobbio, Nolberto, 1992: El futuro de la democracia, Bogotá, Colombia: Fondo de Cultura Económica.

Centro Latinoamericano de Administración para el Desarrollo. CLAD, Una nueva gestión pública para América Latina, 1998.

CORPORACIón Transparencia por Colombia, 2019: Así se mueve la corrupción. Radiografía de los hechos de corrupción en Colombia 2016-2018, Bogotá: Corporación Transparencia por Colombia

Dahl, R, 1956: A Preface to DemocraticTheory. Chicago: The University of Chicago Press.

Departamento Administrativo de la Función Pública, 2018: Guía para la administración del riesgo y el diseño de controles en entidades públicas. Riesgos de Gestión, Corrupción y Seguridad Digital, Bogotá: Departamento Administrativo de la Función Pública.

Durkheim, Emile, 1959: "La democracia”, Revista Mexicana de Sociología, volumen XXI, n 3.

Dworkin, R, 1999: Los Derechos en serio, Barcelona: Ariel Derecho.

Elster, J, 1998: Deliberative democracy, Cambridge: Cambridge University Press.

Estlund, D, 1997: Democracy and Decision: The pure theory of electoral preference, Cambridge: Cambridge University Press.

Ferrajoli, Luigi, 2009: "La democracia política y su crisis actual", Revista Jueces para la democracia, volumen IX, n 65 .

García y Espinosa, 2013: El derecho al estado. Efectos legales del apartheid institucional en Colombia, Bogotá: Dejusticia.

Gargarella, Roberto, 1996, La justicia frente al gobierno. Sobre el carácter contramayoritario del poder judicial, Barcelona: Ariel.

Gargarella, Roberto, 2013: "El nuevo constitucionalismo dialógico, frente al sistema de los frenos y contrapesos", Revista Argentina de Teoría Jurídica, volumen 14, n 2.

Gargarella, Roberto, 2014: Por una justicia dialógica. El poder judicial como promotor de la deliberación democrática, Buenos Aires: Siglo XXI.

Gómez Lee, Iván, 2016: La seguridad jurídica. El caso de la responsabilidad fiscal en Colombia, Bogotá: Universidad Externado de Colombia.

GonzÁlez, Margarita, 1979: Las Rentas del Estado" en Manual de Historia de Colombia, Tomo III, Bogotá, Instituto Colombiano de Cultura.

Hamilton, A; Madison, J y Jay, J, [1787] (1982), The Federalist Papers, New York:

BANTAM Books. 
Hernández, Antonio, 2006: TELECOM, Ganó la Transparencia, ganó la Nación. Bogotá: Contraloría General de la República.

JARAmillo, Jaime y Colmenares, Germán, 1987: Estado, administración y vida política en la sociedad colonial, Tomo I, Colombia, Instituto colombiano de Cultura.

Jiménez, Milton y Arboleda, Paulo, 2017: La garantía judicial de la constitución, Manizales: Universidad de Caldas.

López, Pilar, 2015: Un estado a crédito, Bogotá: Pontificia Universidad Javeriana.

Montaña, Alberto, 2005: El concepto de servicio público en el derecho administrativo, Bogotá: Universidad Externado de Colombia.

Naranjo, R, 2007: Eficacia del Control Fiscal en Colombia. Derecho Comparado. Historia, Macroorganizaciones e instituciones. Bogotá: Universidad del Rosario.

Nino, Carlos, 1997: La constitución de la democracia deliberativa, Barcelona, España: Gedisa.

O’Donnell, G. (1994). Delegative democracy. Journal of Democracy, volumen V, n 1.

O’Donnell, G. (1998). "Accountability horizontal". Revista Agora, volumen VIII, n 5.

Quinche, Manuel, 2015: Derecho Constitucional Colombiano. Bogotá: Editorial Temis.

Robinson y Acemoglu, 2012: Por qué fracasan los países, Bogotá: Deusto.

Schmitt, Carl (1983). Teoría de la Constitución. Madrid: Editorial Tecnos.

Tirado, Álvaro, 1983: Introducción a la bistoria económica de Colombia, Bogotá: El Ancora Editores. Waldron, Jeremy, 2005: Derecho y desacuerdo, Madrid: Editorial Marcial Ponds.

CORTE constitucional de Colombia

\section{Normatividad}

Constitución Política de Colombia, publicada el 4 de julio de 1991.

GACETA del Congreso 153, 2019, publicada el 27 de marzo de 1994.

LEY 23, Por la que se reorganiza la Oficina Nacional de Minas, publicada el 5 de julio de 1923.

LEY 58, Por la que se reforman las leyes orgánicas del Departamento de Contraloría y se dictan otras disposiciones, publicada el 18 de diciembre de 1946.

LEY 20, Por la que se modifican y adicionan las normas orgánicas de la Contraloría General de la República, se fijan sistemas y directrices para el ejercicio del control fiscal y se dictan otras disposiciones, publicada el 28 de abril de 1975.

LEY 5, Por la que se expide el Reglamento del Congreso; el Senado y la Cámara de Representantes, publicada el 18 de junio de 1992.

LEY 42, sobre la organización del sistema de control fiscal financiero y los organismos que lo ejercen, publicada el 27 de enero de 1993.

LEY 136, por la que se dictan normas tendientes a modernizar la organización y el funcionamiento de los municipios, publicada el 2 de junio de 1994.

LEY 489, Por la que se dictan normas sobre la organización y funcionamiento de las entidades del orden nacional, publicada el 29 de diciembre de 1998.

LEY 617, Por la que se reforma parcialmente la Ley 136 de 1994, el Decreto Extraordinario 1222 de 1986, se adiciona la Ley Orgánica de Presupuesto, el Decreto 1421 de 1993, se dictan otras normas tendientes a fortalecer la descentralización, y se dictan normas para la racionalización del gasto público nacional, publicada el 9 de octubre de 2000.

LEY 850, Por medio de la que se reglamentan las veedurías ciudadanas, publicada el 18 de noviembre de 2003. 


\section{Jurisprudencia}

CoRTe Constitucional, sentencia de 24 de septiembre de 1992, rol T-540

Corte Constitucional, sentencia de 24 de agosto de 1995, rol C-374.

Corte Constitucional, sentencia de 2 de diciembre de 1998, rol SU-747

Corte Constitucional, sentencia de 13 de noviembre de 2003, rol C-826.

Corte Constitucional, sentencia de 24 de noviembre de 2004, rol C-1176.

Corte Constitucional, sentencia de 7 de julio de 2006, rol T-517.

Corte Constitucional, sentencia de 12 de julio de.2006, rol C-529.

Corte Constitucional, sentencia de 16 de abril de 2008, rol C-335.

Corte Constitucional, sentencia de 23 de agosto de.2012, rol C-643.

Corte Constitucional, sentencia de 2 de julio de 2014, rol C-418

Corte Constitucional, sentencia de 11 de abril de 2015, rol C-103.

Corte Constitucional, sentencia de 30 de septiembre de 2003, rol C-875.

Corte Constitucional, Sentencia de 21 de noviembre de 2012, rol C- 967.

Corte Constitucional, sentencia de 11 de marzo de 2015, rol C-103.

Corte Constitucional, sentencia de 8 de abril de .2015, rol C-150.

Corte Constitucional, sentencia de 14 de octubre de 2015, rol C-652.

Corte Constitucional, sentencia de 6 de mayo de 2020, rol C-140.

Corte Constitucional, sentencia de 1 de junio de 2016, rol C-285

Corte Constitucional, sentencia de 17 de agosto de 2016, rol C-439.

Corte Constitucional, sentencia de 27 de abril de 2017, rol C-253.

Corte Constitucional, sentencia de 10 de julio de 2019, rol C-306.

Consejo de Estado, sentencia de 10 de mayo 5 de 2007, rol 2003-00182-01 01.

Dictámenes y comunicados de la Contraloría General

Contraloría General de la República, dictamen de 24 de marzo de 2017, Resolución 012.

Contraloría General de la República, Comunicado de 17 de marzo de 2020, 038.

Contraloría General de la República, Comunicado de 19 de marzo de 2020, 041.

Contraloría General de la República, Comunicado de 20 de marzo de 2020, 043;

Contraloría General de la República, Comunicado de 21 de abril de 2020, 058.

Contraloría General de la República, Comunicado de 23 de abril de 2020, 060.

Contraloría General de la República, Comunicado de 23 de abril de 2020, 061.

Contraloría General de la República, Comunicado de 24 de abril de 2020, 062.

Contraloría General de la República, comunicado de 24 de abril de 2020, 063.

Webgrafía

Editorial (20 de mayo de 2014). La DIAN recuperó 222 mil millones en IVA. Recuperado el 1.04.2020, de Diario El Nuevo Siglo: https://elnuevosiglo.com.co/ articulos/5-2014-la-dian-recupero-222-mil-millones-en-iva?page $=2$

Maya, Edgardo (16 de abril de 2015). Control firme. Recuperado el 12.04.2020, de Revista Dinero: http://www.dinero.com/edicion-impresa/pais/articulo/ ejecucion-presupuestal-del-gobierno-colombia/207671 
